\title{
Access all areas
}

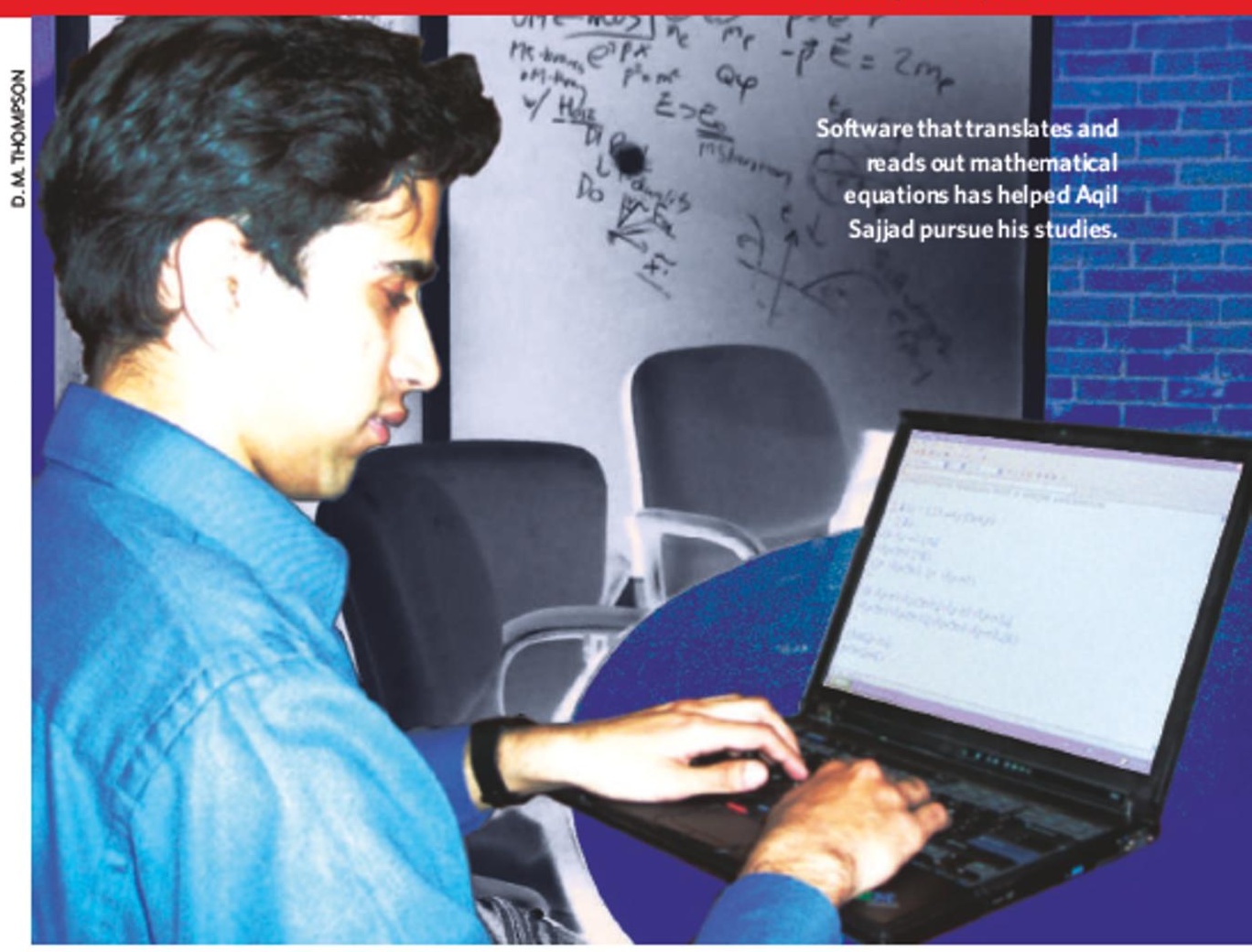

\section{Scientific research can be tricky at the best of times, but people with disabilities face additional challenges both in the lab and when dealing with data. Jessica Ebert meets the researchers who are building their own customized solutions to overcome these problems.}

$1 / \square$ ussia...Sweden...Denmark." A mechanized voice calls out the names of European nations as Stan Berman moves his fingers delicately over the raised dots on a piece of thick white paper. The paper lies on a touchsensitive pad attached to a laptop computer. A map of Europe, formed in outline by small, raised circles, is faintly visible on the paper. Berman, a blind business and technology consultant who provides services for the visually impaired, sits quietly with his eyes closed and head tilted slightly back as the words continue to stream from the computer's speakers. "United Kingdom...Ireland..."

${ }^{\alpha}$ This is quite neat, ${ }^{n}$ he says. Berman and his colleague, Dan Grauman from the National Cancer Institute in Bethesda, Maryland, are sitting in a sunlitkitchen in Columbia, Maryland, to test-drive a gadget known as IVEO - one of the newest assistive technologies for the blind.

IVEO is the brainchild of John Gardner, a solid-state physicist turned entrepreneur who is also blind. It is the latest in a long line of products that he has invented to remove barriers that prevent the visually impaired from fully appreciating maths and science. Like many researchers with disabilities, Gardner had to develop his own technologies for doing science and communicating his work because commercial solutions were seldom available.

"I have a very strong philosophy that we all ought to be reading the same things," says Gardner. "When there isn't a way to do it, we make a way."
Virginia Stern, director of the project on science, technology and disability at the American Association for the Advancement of Science (AAAS) in Washington DC, attributes the advances in assistive technology to the can-do attitude of people with disabilities such as Gardner. "Assistive technology has dramatically changed opportunities for students with disabilities," she says. "It's been the push of the users, some of whom have developed things because they knew what they needed."

Gardner grew up blind in the left eye. Although he also had poor vision in his right eye, "It was correctable enough so I could drive - or as my friends say, 'aim' - a car,' he says.

\section{A difficult lesson}

Gardner's early physics career took him from Texas to Illinois and then to Munich, Germany, where he studied the nuclear magnetic resonance of liquid copper alloys. In 1973, after six years on the physics faculty at the University of Pennsylvania in Philadelphia, he headed west to Oregon State University in Corvallis.

In 1988, Gardner had an operation to treat the glaucoma in his right eye. But rather than slow the loss of vision in that eye, complications left him prematurely blind. "It was not a pleasant time, he recalls.

Although he was away from the lab for a few months, he stopped working for only a couple of days. "I had so many graduate students and postdocs and grants and proposals in the works, I wasn't allowed to be sick," he smiles.
When he finally returned to the lab, he faced a new set of challenges. "I didn't know how to be blind, he explains. "No one knew what to do with me."

Initially, Gardner's students would taperecord journal papers for him and try to describe what their data looked like by taking his finger and tracing the curves in a graph or a picture. It took him months to discover that blind people could use computers. "I had a computer that was just sitting and gathering dust in my office, he says.

He can still recall the time he was introduced to screen readers, the software that converts what is displayed on a computer screen into either audio or a Braille output that can be read on a special keyboard. "That was one of the better days, 'he says.

From that moment on, Gardner began inventing tools that allowed him to continue his lab work. He never planned to abandon physics in pursuit of his innovations, but there was such an unmet need for the tools that he found himself moving in that direction. "I didn't really want to become an entrepreneur," he says, "but someone had to."

In the early 1990s, Gardner was awarded a grant from the National Science Foundation (NSF) to establish the Science Access Project at Oregon. In the past ten years, the projecthas developed technologies to overcome the biggest barriers for those with poor vision: reading and writing mathematical and scientific notation, and viewing graphs, tables, charts and diagrams. 


\section{Breaking down the barriers}

"Helen Keller once said that blindness isolates you from things, but deafness isolates you from people," says Jane Dillehay, a deaf molecular biologist at Gallaudet University in Washington DC, which caters exclusively for deaf people. "Science is a communal enterprise and depends on people sharing their research with each other." The largest barrier for a deaf scientist is engaging in the spontaneous conversations that occur around the lunch table or in the hallways at conferences.

At conferences, the assistance of sign-language interpreters is really important, says Caroline Solomon, a marine biologist at Gallaudet. If interpreters are not available, she uses remotecaptioning services to follow lectures. This is fine in the lecture hall, but Solomon dreams of a portable device to facilitate two-way conversation s between a hearing and a deaf person. People are working on such tools, but "the technology cannot handle the average person with an unpredictablevocabulary and it is also not yet portable", says Dillehay.

The Internet has had the biggest impact on dialogue between the deaf and hearing "I think the popularization of e-mail has been the greatest accessibility tool for the deaf community," says Derek

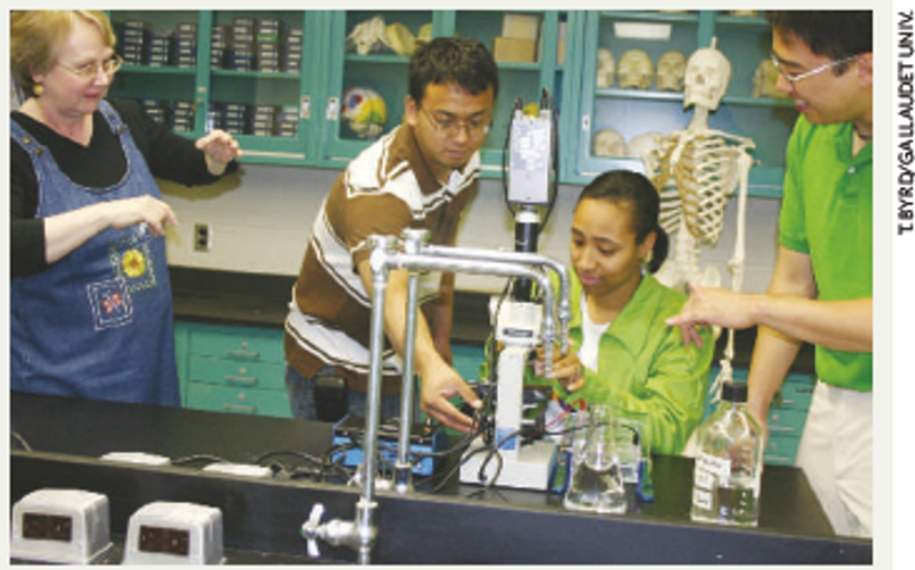

Jane Dillehay uses sign language to teach biology students.

Braun, a professor of molecular biology at Gallaudet who also conducts research at the US
National Cancer Institute. "In fact, some of my collaborators probably do notrealize that I am deaf." J.E.
Today, Gardner is demonstrating IVEO to Grauman and Berman. Grauman's job as an information technologist at the National Cancer Institute includes making sure that maps showing cancer mortality across the United States can be used by everyone. Since 1998, federal agencies have been required to make their information and technology, including websites, operating systems and kiosks, accessible to people with disabilities.

\section{All mapped out}

Although the maps Grauman has developed meet federal requirements, problems remain. "They don't give the blind user the relative location of the states," he explains. IVEO is expected to change that. "The beauty of the touchpad is that it will permit the blind user to move east and west, or north and south, and actually 'see' whether there are neighbouring states with high cancer mortality rates," he says.

Universal access to the products of scientific research - from public-health information to data on envi-

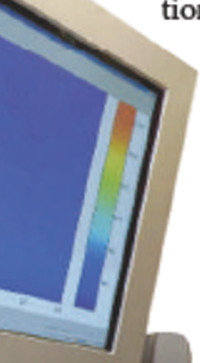
ronmental pollutants - is just one aspect of assistive technology. But for students with disabilities, having access to the right technology can determine whether they choose to enter science at all. That was true for Aqil Sajjad, a physics student from Pakistan, who says that the specialized software WinTriangle, which helps the visually impaired read and write mathematics, was a lifeline.

Sajjad lost his eyesight in 1996 at the age of 16. Although science had intrigued him from a young age, he couldn't get the support he needed to study physics in his homeland. $\mathrm{He}$ began searching the Internet for educational opportunities in the United States because he knew the 1990 Americans with Disabilities Act had opened new doors for students with disabilities.

At some point during his search, Sajjad stumbled on the work of Gardner's Science Access Project and knew that this was where he wanted to pursue his passion for physics. ${ }^{\alpha}$ It was crucial for my decision that Gardner

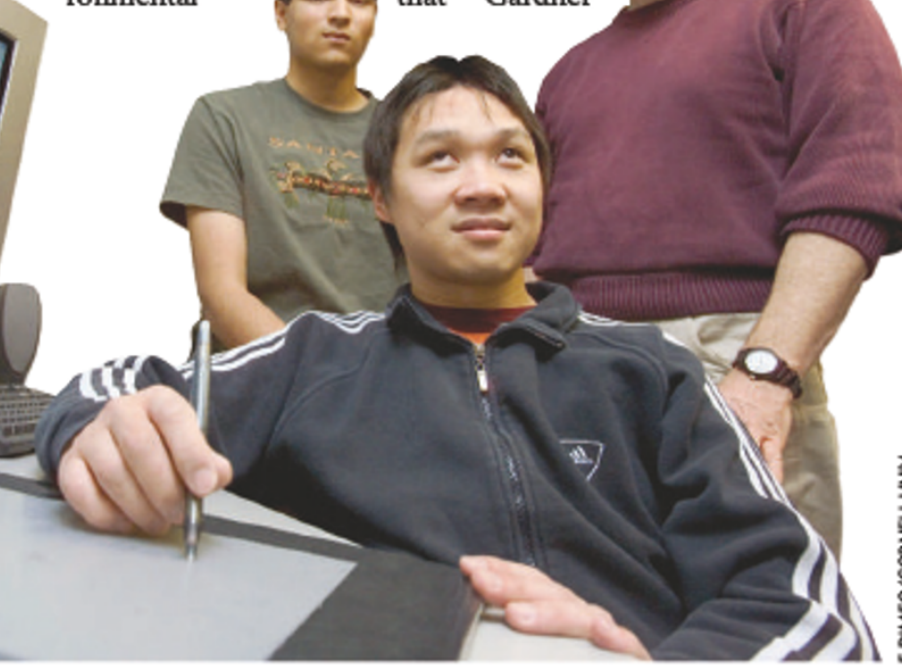

was a blind physicist and was developing these tools, he recalls. "WinTriangle turned out to be the thing I needed.

WinTriangle, which was produced by the Science Access Project, allows a blind user to write mathematical equations, perform calculations and hear mathematical text. In its simplest form it is a scientific word processor with a specialized set of fonts representing symbols and operations that can be read by a speech synthesizer.

Sajjad has now moved on and is a first-year doctoral student in theoretical physics at Harvard University in Boston, Massachusetts. Here, physicists write papers using a typesetting language called LaTeX, so David Thompson, a fellow student, wrote a software program to convert LaTeX into WinTriangle. "The concept behind this is so simple," says Thompson, but the significance for Sajjad is enormous. "We're completing the path of communication of maths between blind and sighted communities," he explains.

\section{Open access}

Thompson and the Adaptive Technology Laboratory at Harvard are now ironing out some of the glitches in the program and adding features to the converter to make it more robust, such as improving the quality of the voice synthesizer and adding more keyboard shortcuts. ${ }^{\alpha}$ Having the converter makes a huge amount of information available to me," says Sajjad. "It has made a big difference in terms of levelling the playing field between me and other people."

WinTriangle is 'open-source' software, which lets users adapt and rewrite it to meet their needs. It is fairly common for assistive technologies to be modified or enhanced by their users. Gardner recently teamed up with

\section{Tunedin: the colours on the map of the upper} atmosphere can be turned into musical notes for blind student Victor Wong (front), thanks to work by Ankur Moitra (rear left) and James Ferwerda. 
Victor Wong, James Ferwerda and Ankur Moitra at Cornell University in Ithaca, New York, who have developed software that translates colour pixels on a computer screen into piano notes. The group hopes to combine the audio software with IVEO's tactile technology to solve a particularly challenging information problem.

Wong, who lost his sight in an accident when he was seven, works with a team that studies the ionosphere, the layer of the atmosphere between Earth and space. Part of Wong's work involves reading maps of the ionosphere in which colours represent variables such as electron density and light intensity. ${ }^{\alpha}$ To be able to visualize a map is a very basic need," says Wong. "There is no way to handle the image problem right now."

With the Cornell system, Wong uses a touch-sensitive tablet to explore three-dimensional images with a 'wireless' electronic pen. ${ }^{\alpha}$ When you move the pen around on the tablet it's the same as looking around on the screen," explains Wong.

When using the tablet, Wong finds the pen is almost too sensitive - it is actually better than the naked eye and gives too much detail. In addition, there is no easy way to uncover the major features of an image without tedious, pixel-by-pixel exploration.

\section{Sound investment}

This is where Gardner comes in. By combining IVEO's ability to display tactile maps with the Cornell team's software for converting colour into sound, users will be able to determine the boundaries of a map or graph more easily. ${ }^{\alpha}$ This is about finding a way to make graphical information accessible to the blind and those with print disabilities," says Gardner. ${ }^{\alpha}$ That is still one of the biggest barriers."

But not all of the barriers are technological. "Widespread use of these technologies requires both money and cultural adjustments," he says.

“The latter is the hardest to achieve."

Stern agrees. "Counsellors and teachers at all levels, from preschool through to the very critical high-school years, do not believe that students with disabilities can persist and excel in science and engineering fields," she says. "One reason is there aren't enough role models." In addition, she says, few students, counsellors, teachers or employers know about assistive technologies. And for some people, such technology doesn't yet go quite far enough (see 'Breaking down the barriers", previous page).

This may be reflected in the low number of disabled researchers. In 2000, the NSF estimated that 365,500 people with disabilities were employed in science, technology, engineering and mathematics (STEM) in the United States

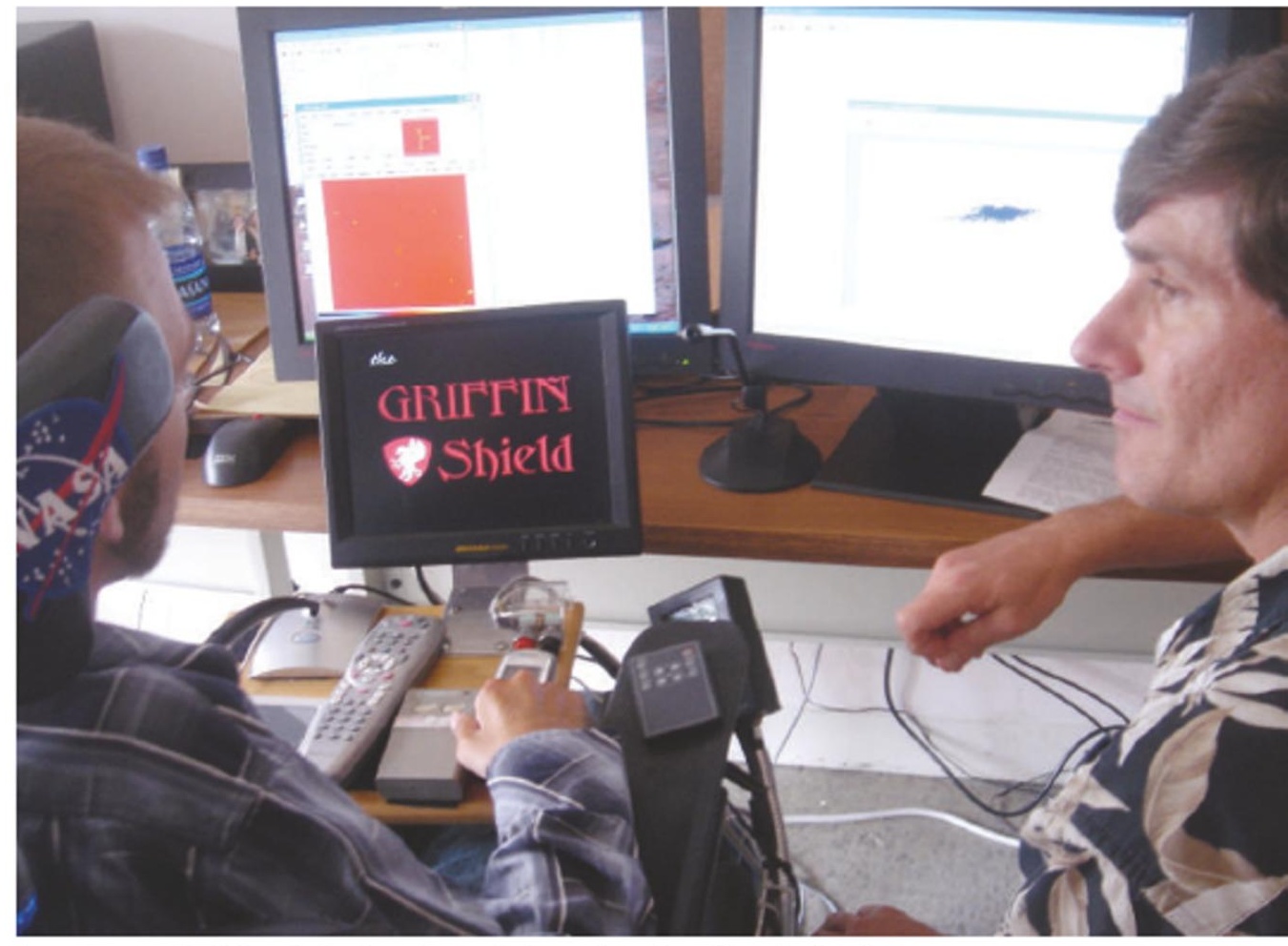

Jesse Leaman (left) has devised an electronic 'rear-view mirror' for wheelchair users.

- about $7 \%$ of the science workforce. But there are more people with disabilities in the general workforce (13\%), and even the college-educated workforce (9\%). ${ }^{\alpha}$ There is a strong underrepresentation of persons with disabilities in STEM fields, especially at the $\mathrm{PhD}$ level, ${ }^{\text {, says }}$ Ted Conway, director of an NSF programme researching disabilities education.

Gardner is optimistic about the future, but sees change happening slowly. 'I don't want to be too negative, he says. "I am optimistic about public awareness and new technologies. I believe that things are getting better, but it would be dishonest to say that things are alreadybetter"

One student who has persisted in the face of these challenges is Jesse Leaman. Despite being paralysed from the neck down ever since an accident when he was 18 , Leaman has pursued a career in astronomy and graduated from the University of Maryland in College Park in 2002. During his time there, Leaman participated in a AAAS programme that places disabled students with an aptitude and passion for science into summer internships with research agencies or companies.

In 1998, Leaman spent the summer working in the microgravity department at NASA's Marshall Space Flight Center in Huntsville, Alabama, where he designed educational web pages about the working environment aboard the International Space Station. The next summer, he worked as an intern in the space science department at NASA's Goddard
Space Flight Center in Greenbelt, Maryland. Using voice-activation software called Dragon Naturally Speaking, he ran satellite data through an analysis program to study how the solar wind interacts with Earth's electric field.

It was during these internships that Leaman developed what he calls the Griffin Shield, a navigation and communication system for motorized wheelchairs and scooters. Leaman kept colliding with people and objects while manoeuvring in hallways and offices, so with the help of NASA technologists, he attached a small video camera to the rear of his wheelchair and an LCD monitor to the front. In effect, he now has an electronic 'rear-view mirror', powered by the chair's battery, which can also be hooked up to a laptop for communication purposes.

Leaman designed the Griffin Shield out of necessity and never imagined he would one day establish his own business. But when the shield turned out to be so practical and convenient, he says, "I knew I wanted to share it with other wheelchair users".

Next year, Leaman will receive his doctorate in astronomy from the University of California, Berkeley, and plans to continue collaborating with astronomers at Goddard. $\mathrm{He}$ is currently working on determining the rate at which supernovae occur.

$\mathrm{He}$ is also in the process of mass-producing the Griffin Shield and negotiating contracts with major wheelchair manufacturers. But unlike Gardner, Leaman has no intention of giving up his love for astronomy. "I can do both," he says.

Jessica Ebert is an intern in Nature's

Washington DC office. 